expected. It is clear that mammalian development requires the functional and complementary presence of at least parts of both maternal and paternal genome. Affects on embryonic and fetal growth and behaviour have been observed. The challenge now is to determine how many childhood and adult disorders also are associated with genomic imprinting.

JUDITH G HALL

Department of Medical Genetics,

The University of British Columbia,

University Hospital-Shaughnessy Site,

4500 Oak Street,

Vancouver, $B C$,

Canada V6H $3 N I$

1 Hall JG. Genomic imprinting-review and relevance to human diseases. Am f Hum Genet 1990;46:103-23.

2 Solter D. Differential imprinting and expression of maternal and paternal genomes. Annu Rev Genet 1988;22:127-46.

3 Surani MAH. Evidences and consequences of differences between maternal and paternal genomes during embryogenesis in the mouse. In: Rossan J, Pederson RA, eds. Experimental approaches to mammalian embryonic development. Cambridge: Cambridge University Press, 1986:401-35.
4 Searle AG, Beechey CV. Noncomplemetation phenomena and their bearing on nondisjunctional effects. In: Dellarcho VL, Voytek PE, Hollaender A, on nondisjunctional effects. In: Dellarcho VL, Voytek PE, Holl

5 Lyon MF, Glenister PH. Factors affecting the observed number of young resulting from adjacent-2 disjunction in mice carrying a translocation. Genet Res 1977;29:83-92.

6 Cattanach BM, Kirk M. Differential activity of maternally and paternally derived chromosome regions in mice. Nature 1985;315:496-8.

7 Spence JE, Perciaccante RG, Greig GM, et al. Uniparental disomy as a mechanism for human genetic disease. Am f Hum Genet 1988;42:217-26.

8 Voss R, Ben-Simon E, Avital A, et al. Isodisomy of chromosome 7 in a patient with cystic fibrosis: could uniparental disomy be common in humans? Am f Hum Genet 1989;45:373-80.

9 Nicholls RD, Knoll JHM, Butler MG, Karam S, Lalande M. Genetic imprinting suggested by maternal hetrodisomy in non-deletion Prader-Willi syndrome. Nature 1989;342:281-5.

10 Searle AG, Peters J, Lyon MF, et al. Chromosome maps of man and mouse. IV. Ann Hum Genet 1989;53:89-140.

11 Magenis ER, Brown MG, Lacy DA, Budden S, LaFranchi S. Is Angelman syndrome an alternate result of del(15)(q1lq13)? Am $\mathcal{F}$ Med Genet 1987;28: syndron 829 . 38 .

12 Schroeder WT, Chao LY, Dao DD, et al. Nonrandom loss of maternal chromosome 11 alleles in Wilms tumour. Am $\mathcal{F}$ Hum Genet 1987;40:413-20.

13 Grundy P, Koufos A, Morgan K, Li FP, Meadows AT, Cavence WK. Familial predisposition to Wilms' tumour does not map to the short arm of chromosome 11. Nature 1988;336:374-6.

14 Toguchida J, Ishizaki K, Sasaki MS, et al. Preferential mutation of paternally derived RB gene as the initial event in sporadic osteosarcoma. Nature 1989; 338:156-8.

15 Sapienza C. Genome imprinting and dominance modification. Ann NY Acad Sci 1989;564:24-38.

16 Surani MA, Reik W, Allen ND. Transgenes as molecular probes for genomic imprinting. Trends in Genetics 1988;4:59-62.

\title{
Neonatal infections with coagulase negative staphylococci
}

Staphylococci are members of the family of bacteria Micrococcaceae. They are Gram positive, catalase positive cocci that form grape like clusters (from the Greek staphyle: bunch of grapes, coccus: grain or berry). The classification of staphylococci is extremely complex and has been revised repeatedly over the last 30 years. More and more new species have been recognised, so that there are now 19 distinct species recognised by Bergey's Manual of Systematic Bacteriology (1986). The coagulase test is one of several tests used by clinical laboratories to distinguish Staphylococcus aureus from other staphylococci. 'Coagulase negative staphylococci' is a term used to describe species that do not coagulate plasma under the defined conditions of the coagulase test.

Coagulase negative staphylococci are frequent blood culture isolates from neonates in many intensive care units. $^{12}$ Neonatal infections with coagulase negative staphylococci are hospital acquired and are usually diagnosed after the first week of postnatal life. ${ }^{3}$ Quantitative blood culture techniques have shown that the numbers of coagulase negative staphylococci in the blood of premature neonates with bacteraemia may exceed 1000 colony forming units $/ \mathrm{ml}^{45}$ Defective opsonisation and phagocytosis may allow these large numbers of coagulase negative staphylococci to circulate. ${ }^{6}$ Staphylococcus epidermis is the species most frequently associated with neonatal infection, ${ }^{7}$ although other species such as Staphylococcus hominis, Staphylococcus warneri, and Staphylococcus haemolyticus have also been implicated. The strains involved in neonatal infection are usually resistant to a wide range of antibiotics. ${ }^{8}$ Antibiotic resistant strains are spread from neonate to neonate on the hands of medical and nursing staff leading to colonisation of the skin of premature neonates in intensive care units within the first week of life. ${ }^{9}$ Apart from the skin, another major reservoir of antibiotic resistant coagulase negative staphylococci is the bowel of neonates, where numbers may exceed $10^{10}$ colony forming units/g dry weight.
Many strains of coagulase negative staphylococci secrete a complex mucopolysaccharide, ${ }^{10}$ which has been termed 'extracellular slime substance'. Electron microscopy studies suggest that it stabilises the attachment of coagulase negative staphylococci to the surfaces of foreign bodies such as intravascular catheters. ${ }^{11}$ The influence of extracellular slime substance on the adherence of coagulase negative staphylococci to the immature skin of premature neonates is not known. Extracellular slime substance has been reported to have a number of immunomodulating effects such as inhibiting antibody binding to the staphylococcal cell wall, reducing the chemotactic response of neutrophils, and interfering with $\mathrm{T}$ and $\mathrm{B}$ cell function. ${ }^{12}$ Although extracellular slime substance is probably important in stabilising the attachment of bacteria on surfaces, its importance in determining pathogenicity is controversial. ${ }^{13}$ It is not produced by all clinically significant isolates of coagulase negative staphylococci and other bacterial surface characteristics such as bacterial cell surface hydrophobicity may be more important determinants of pathogenicity. ${ }^{714}$

It is not possible to sterilise the skin and therefore a proportion of percutaneously collected samples will be contaminated with cutaneous flora. Use of quantitative blood culture techniques may help to differentiate blood culture contamination from bacteraemia. ${ }^{45}$ The proportion of blood cultures collected from neonates and children that are contaminated with coagulase negative staphylococci has been estimated at $7-10 \% .^{515}$ This proportion is similar to that reported for blood cultures collected from neonates with necrotising enterocolitis. ${ }^{16}$

There is no evidence that coagulase negative staphylococci can cross intact skin. Intravascular catheters frequently become colonised with antibiotic resistant strains, ${ }^{17}$ and neonatal bacteraemia with coagulase negative staphylococci is frequently associated with the use of intravascular catheters. ${ }^{418}$ It is likely that infected catheters are the most common source of neonatal infection with coagulase negative staphylococci. The mechanisms by which bacteria 
colonise intravascular catheters are poorly understood. Bacteria may be washed into the catheter after contamination of infused fluids or migrate from the cutaneous surface along the outside of the catheter. The relative importance of these two routes of catheter colonisation in neonates is not known. In addition to catheter associated infections, coagulase negative staphylococci may cause wound infections and urinary tract infections after urological surgery. Meningitis with coagulase negative staphylococci in neonates is usually associated with ventricular drainage devices. The clinical signs of bacterial infection in neonates are nonspecific. Rapid tests such as buffy coat examination ${ }^{19} 20$ and tests for neutrophil activation or acute phase protein response $^{20-22}$ may improve the accuracy of diagnosis at the onset of episodes of suspected infection.

In contrast to Gram negative infections, neonatal mortality associated with infections caused by coagulase negative staphylococci is unusual. The clinical signs of infections with coagulase negative staphylococci are often minor with insidious onset of signs such as lethargy, increased frequency of apnoea, hypotonia, and poor peripheral perfusion. Delayed treatment may lead to disseminated disease, however, ${ }^{18}$ and so treatment with an appropriate antibiotic should be initiated as soon as infection with coagulase negative staphylococci is suspected and the appropriate diagnostic samples have been taken. Isolates of coagulase negative staphylococci from neonates are often resistant to penicillin and aminoglycosides, but are also commonly resistant to a range of other antibiotics such as chloramphenicol, cloxacillin, and erythromycin. Unless specific tests are performed, resistance to $\beta$-lactam antibiotics may not be detected by the laboratory. Resistance of neonatal coagulase negative staphylococcal isolates to the glycopeptide antibiotics, vancomycin and teicoplanin, has not been reported and these are the antibiotics of choice for treating suspected neonatal infections with coagulase negative staphylococci. Strains of vancomycin resistant $S$ haemolyticus were isolated from the peritoneal dialysis fluid of an adult. ${ }^{23}$ Rifampicin inhibits a wide range of micro-organisms, including staphylococci at very low concentrations, but must be used with another antibiotic to avoid the rapid emergence of rifampicin resistance. Ventriculitis or meningitis associated with use of intraventricular drainage devices can be controlled with intravenous vancomycin combined with oral or intravenous rifampicin, but eradication of the infection usually requires removal of the colonised device. In neonates with suspected catheter associated infections, peripheral intravenous catheters associated with local signs of inflammation should be removed. Whether or not central lines colonised with coagulase negative staphylococci should be removed from neonates is controversial. There are no published comparative studies of treatment regimes for neonates with infected central lines.

The frequency of neonatal infection with coagulase negative staphylococci may be reduced by restricting the duration of use of intravascular catheters, avoidance of contamination of infusion system connections, better care of the catheter insertion site, and delegation of responsibility for the management of central lines to a specialist team. Better understanding of the mechanisms leading to bacterial colonisation of catheters and of the interaction between intravascular catheters and developing skin may lead to new strategies for preventing infections with coagulase negative staphylococci in premature neonates.

Departments of Microbiology and Paediatrics,

M R MILLAR N TODD

Level D, The Clarendon Wing,

The General Infirmary,

Leeds LS2 9NS

P MACKAY

1 Battisti O, Mitchison R, Davies PA. Changing blood culture isolates in a regional referral intensive care unit. Arch Dis Child 1981;56:775-8.

2 Freedman RM, Ingram DL, Gross I, et al. A half century of neonatal sepsis at York 1928-1978. Am 7 Dis Child 1981;140:140-5.

3 Freeman J, Platt R, Sidebottom DG, Leclair JM, Epstein MF, Goldmann DA. Coagulase-negative staphylococcal bacteremia in the changing neonatal intensive care unit population. $\mathcal{F} A M A$ 1987;258:2548-52.

4 Kite P, Langdale V, Todd N, Millar MR, Mackay P. Direct isolation of coagulase-negative staphylococci from neonatal blood samples. $\mathcal{F}$ Hosp coagulase-negative stap
Infect 1989;14:135-40.

5 Phillips SE, Bradley JS. Bacteremia detected by lysis direct plating in a neonatal intensive care unit. $\mathcal{J}$ Clin Microbiol 1990;28:1-4.

6 Freer A, Gerards LJ, Aerts P, Westerdaal NAC, Senders RC, van Dijk H, Verhoef J. Opsonic defense to Staphylococcus epidermis in the premature nerhoef J. Opsonic defense to Staphy

7 Martin MA, Pfaller MA, Massanari RM, Wenzel RP. Use of cellular hydrophobicity, slime production, and species identification markers for the clinical significance of coagulase-negative staphylococcal isolates. Am $\mathcal{f}$ Infect Control 1989;17:130-5.

8 Hall RT, Hall SL, Barnes WG, et al. Characteristics of coagulase-negative staphylococci from infants with bacteremia. Pediatr Infect Dis 1987;6: 377-83.

9 D'Angio CT, McGowan KL, Baumgart S, Geme J St, Harris MC. Surface colonization with coagulase-negative staphylocci in premature neonates. f Pediatr 1989;114:1029-34.

10 Bayston R, Penny SR. Excessive production of mucoid substance in staphylococcus S11A: a possible factor in colonization of Holter shunts. Dev Med Child Neurol 1972;14 (suppl 27):25-8.

11 Franson TR, Sheth NK, Rose HD, Sohnle PG. Scanning electron microscopy of bacteria adherent to intravascular catheters. $\mathcal{F}$ Clin Microbiol 1984;20: $500-5$.

12 Peters G, Gray ED, Johnson GM. Immunomodulating properties of extracellular slime substance. In: Bisno AL, Waldvogel FA, eds. Infections extracellular stime substance. In: Bisno AL, Wadvogel FA, eds. Infections associated with indwelling medical device

13 Pfaller MA, Herwald LA. Laboratory, clinical, and epidemiological aspects of coagulase-negative staphylococci. Clinical Microbiology Reviews 1988;1: 281-99.

14 Van-Bronswijk H, Verbrugh HA, Heezius HC, et al. Heterogeneity in opsonic requirements of Staphylococcus epidermidis: relative importance of surface hydrophobicity, capsules and slime. Immunology 1989;67:81-6.

15 Carey RB. Clinical comparison of the isolator 1.5 microbial tube and the bactec radiometric system for detection of bacteremia in children. $\mathcal{f}$ Clin Microbiol 1984;19:634-8.

16 Palmer SR, Biffin A, Gamsu HR. Outcome of neonatal necrotising enterocolitis: results of the BAPM/CDSC surveillance survey, 1981-1984. Arch Dis Child 1989;64:388-94.

17 Peters G, Locci R, Pulverer G. Adherence of coagulase-negative staphylococci on surfaces of intravenous catheters. $\mathcal{F}$ Infect Dis 1982;146:479-82.

18 Noel GJ, Edelson PJ. Staphylococcus epidermidis bacteremia in neonates: further observations and the occurrence of focal infections. Pediatrics further observatio

19 Klieman MB, Reynolds JK, Shreiner RL, et al. Rapid diagnosis of neonatal bacteremia with acridine orange. F Pediatr 1984;105:419-21.

20 Kite P, Millar MR, Gorham P, Congdon P. Comparison of tests used in diagnosis of neonatal bacteraemia. Arch Dis Child 1988;63:639-40.

21 Boyle RJ, Chandler BD, Stonestreet BS, Oh W. Early identification of sepsis in infants with respiratory distress. Pediatrics 1978;62:744-50.

22 Philip AGS, Hewitt JR. Early diagnosis of neonatal sepsis. Pediatrics 1980 65:1036-41.

23 Schwalbe RS, Stapleton JT, Gilligan PH. Emergence of vancomycin resistance in coagulase-negative staphylococci. N Engl f Med 1987;316: 927-31. 